\title{
Should dental amalgams be used in dental training? The perspectives of dental academics at a university in South Africa
}

SADJ October 2021, Vol. 76 No. 9 p524 - p531

S Bissoon', R Moodley²

\section{ABSTRACT}

\section{Introduction}

Dental amalgam has been used in dentistry for the last 150 years to restore posterior teeth. Concerns regarding the safety issues with amalgam due to its mercury content have lead to the introduction of composite dental material to restore posterior teeth. This has transformed the teaching and training trends of direct restorative materials for posterior teeth.

\section{Objectives}

This descriptive study aimed to gain insight into academic staff and clinical supervisors' perceptions regarding the use of dental amalgams in the teaching of restorative dentistry.

\section{Methods}

This study used a qualitative method of data collection. Two focus group discussions were conducted between March and May 2020.

\section{Results}

Seventeen participants were invited to participate. Fourteen responded and participated, yielding an $82 \%$ response rate. The data identified two major themes, viz. the challenges experienced with the teaching of dental amalgam and curriculum development recommendations. Clinical quota requirements, disposal of waste products, and occupational and environmental risks regarding mercury exposure were sub-themes. Some of the curriculum recommendations

\section{Author affiliations:}

1. Sharmila Bissoon: B. $O H, B D T, D P H$. Masters Student, Discipline of Dentistry, University of KwaZulu-Natal, Private Bag X54001, Durban, 4001, South Africa. sharmilajobraj@gmail.com

2. Dr Rajeshree Moodley: PhD, Lecturer, Discipline of Dentistry, University of KwaZulu-Natal, Private Bag X54001, Durban, 4001, South Africa. moodleyra@ukzn.ac.za. ORCID ID https://orcid. org/0000-0003-2703-9370

Corresponding author:

Dr Rajeshree Moodley: University of KwaZulu-Natal

Email: moodleyra@ukzn.ac.za

\section{Author contributions:}

1. Sharmila Bissoon: was responsible for conceptualisation, data collection and data analysis

2. Dr Rajeshree Moodley: was responsible for research supervision, study design and manuscript review. included the skills gained during cavity preparations, the training and quota requirements of dental materials, and teaching trends locally, nationally and internationally.

\section{Conclusion}

This study revealed that dental amalgam is still an integral part of the restorative dentistry curriculum at the university. However, the teaching of resin composite now occupies more than fifty percent of the restorative dentistry curriculum. Academics and clinical supervisors show a greater affinity for the placement of composite restorations.

\section{Keywords}

dental amalgam; composite resin; dental curriculum; dental education; restorative dentistry, dental materials

\section{INTRODUCTION}

Dental caries, commonly known as tooth decay or dental cavities, are considered one of the most common noncommunicable diseases worldwide. ${ }^{1}$ Caries results in the early stages of enamel breakdown, spreading into the dentin layer and causing tooth sensitivity and pain. At this stage, a tooth has to be restored by a dental professional. ${ }^{2}$ The direct restorative material commonly used is either dental amalgam or resin composite. ${ }^{3}$ Dental amalgam has been used in dentistry to restore posterior teeth for the last 150 years. Concerns regarding the safety issues with dental amalgam and its mercury content, have resulted in the introduction of resin composite material to restore posterior teeth. ${ }^{4}$ Resin-based composites have been used to restore teeth for approximately 60 years. ${ }^{5}$ The move towards resinbased composite material in dentistry has transformed the teaching and training of direct restoration materials. ${ }^{6}$ There have been variations in the teaching with dental amalgam globally, with some countries completely stopping, while other countries are still teaching students with it. ${ }^{7}$

Undergraduates placed in the United Kingdom dental schools have gained more experience in composite restorations than dental amalgam. ${ }^{8}$ Moreover, dental amalgam is no longer used in paediatric dentistry. ${ }^{8}$ Other studies conducted by Lynch and Wilson (2013) found that posterior composites' teaching is also well established in Ireland, Brazil, USA, Japan, Canada, and Spain. It was established that students in the UK are more adept with composite restorations, emphasising the minimally 


\begin{tabular}{|c|c|c|c|c|}
\hline & & Focus group $1(n=6)$ & Focus group $2(n=8)$ & Total $(n=14)$ \\
\hline \multirow{2}{*}{ Gender } & Males & 3 & 2 & 5 \\
\hline & Females & 3 & 6 & 9 \\
\hline \multirow{4}{*}{$\begin{array}{l}\text { Work experience } \\
\text { (years) }\end{array}$} & $<5$ & 1 & 0 & 1 \\
\hline & $5-10$ & 1 & 1 & 2 \\
\hline & $11-19$ & 1 & 1 & 2 \\
\hline & $20-29$ & 3 & 6 & 9 \\
\hline \multirow{4}{*}{ Educational Qualification } & Undergraduate & 6 & 2 & 8 \\
\hline & Postgraduate & & & \\
\hline & Masters & 0 & 2 & 2 \\
\hline & $\mathrm{PhD}$ & 0 & 4 & 4 \\
\hline \multirow{4}{*}{ Clinical Position } & Dentist & 4 & 1 & 5 \\
\hline & Dental therapist & 2 & 2 & 4 \\
\hline & $\begin{array}{c}\text { Oral hygienist } \\
\text { (dual qualified as a hygienist } \\
\text { and dental therapist) }\end{array}$ & 0 & 1 & 1 \\
\hline & Lecturer & 0 & 5 & 5 \\
\hline \multirow{3}{*}{ Place of work } & Private practice & 0 & 3 & 3 \\
\hline & Department of Health & 6 & 0 & 6 \\
\hline & University & 0 & 5 & 5 \\
\hline \multirow{3}{*}{ Dental supervision (years) } & $<5$ & 2 & 0 & 2 \\
\hline & $5-10$ & 4 & 2 & 6 \\
\hline & $11-15$ & 0 & 6 & 6 \\
\hline \multirow{2}{*}{$\begin{array}{l}\text { Involvement in dental } \\
\text { curriculum planning }\end{array}$} & Yes & 1 & 4 & 5 \\
\hline & No & 5 & 4 & 9 \\
\hline
\end{tabular}

interventive technique of dentistry. ${ }^{7}$ Health authorities in the European Union have worked together with dental schools to reduce amalgam usage. Dental schools in the Netherlands stopped teaching restorative techniques with amalgam between 1995 and 2005. In the early 2000s, Sweden emphasised teaching resin composites with minimal time spent on the theory component of dental amalgam. ${ }^{9}$ Schools in Denmark actively encourage the placement of composite restorations, while in Japan, 93\% of dental schools emphasise the teaching of mercuryfree restorations. Sweden, Germany and Norway have completely restricted dental amalgam due to environmental issues. $^{9}$

A study in Saudi Arabia found that students in both the government and private dental schools felt more confident with the placement of composite restorations than amalgam. However, both schools felt that amalgam should not be replaced entirely by composite. ${ }^{10}$ Participants in an Australian study strongly agreed that $80 \%$ of teaching should be conducted using composite restorations and not amalgam. ${ }^{11}$ A study conducted among dental schools in North America revealed that $97 \%$ of dental schools still conduct teaching with dental amalgam. However, most of them revealed that the teaching time allocated to amalgam is approximately $30 \% .{ }^{12}$ It was found that the teaching of dental amalgam is still widely emphasised in Nigeria. Students were more likely to place amalgam (60\%) restorations than resin composite. ${ }^{13}$ However, one dental school in Nigeria is determined to move towards mercury-free dental materials. It has already stopped placing amalgam restorations in children's teeth. ${ }^{13}$

This descriptive study aimed to determine dental academic perceptions regarding the teaching of amalgam in a dental school in South Africa. This was the first time a study of this type regarding dental therapists' training was carried out. The scope of training of dental therapists in South Africa includes examining a patient, restoration of primary and permanent teeth, scaling and polishing, taking dental radiographs, administering local anaesthesia, health education and promotion, and diagnosing common oral diseases. In addition, a targeted review of the curriculum was also conducted.

\section{METHODS}

Research setting and context

The study was located within a dental school in South Africa. Two programs are offered at this institution: B. Dental Therapy and B. Oral Hygiene. The study was conducted between March and May 2020. Ethical approval was granted from the Social Sciences and Humanities Ethics Committee of the University of KwaZulu-Natal (HSSREC/00000622/2019) and gatekeeper permission from the clinical training head and the registrar.

\section{Research design}

This descriptive study used a qualitative method for data collection. It was conducted to gain insights into dental amalgam usage in dental training.

\section{Participants}

All academic and clinical staff involved in the teaching and supervision of restorative dentistry were invited $(n=17)$. A purposive sampling method was used to identify participants. The participants included dentists and dental therapists. All participants agreed to participate in the study as well as to an audio recording of the discussions. In addition, a targeted review of the curriculum was conducted using a self developed checklist. 


\begin{tabular}{|c|c|c|}
\hline Sub-theme & Description & Participants Response \\
\hline $\begin{array}{l}\text { 1.Increase in student intake } \\
\text { at the university }\end{array}$ & $\begin{array}{l}\text { Student numbers have increased } \\
\text { to cope with the increased health } \\
\text { demands for dental therapists }\end{array}$ & $\begin{array}{l}\text { Focus group 2, P7: 'The numbers have increased in the class, puts a lot of pressure on } \\
\text { the full-time staff or whatever staff...too many of them (students)and I think that it is a } \\
\text { problem.' } \\
\text { Focus group , Pii: 'The trend has changed not only because it is driven by the curriculum } \\
\text { but also driven by the student numbers. And it is also driven by the amount of time that } \\
\text { you have to train the students, the time has been greatly reduced, the student numbers } \\
\text { have increased drastically, So the cut down in time has obviously impacted on that. so } \\
\text { previously, there has always been enough time allocated for that.' }\end{array}$ \\
\hline $\begin{array}{l}\text { 2.Clinical quota require- } \\
\text { ments for composite and } \\
\text { amalgam restorations }\end{array}$ & $\begin{array}{l}\text { Students must complete composite } \\
\text { restorations and amalgam resto- } \\
\text { rations in the clinic }\end{array}$ & $\begin{array}{l}\text { Focus group 1, Piv: 'so I think it's almost unfair to say for the sake of the quota that you } \\
\text { must have this (amalgam). Because at the end of the day, let the patient decide what } \\
\text { they want.' } \\
\text { Focus group 2, P8: 'because it's a teaching institution, students have to do a certain } \\
\text { amount of amalgams per year. They have to complete their quotas...' } \\
\text { Focus group 2, P6: 'If you look at previous years, most students do not complete the } \\
\text { amalgam quota. Towards the end (of the year), you find that most students are scram- } \\
\text { bling to find patients. You find that a tooth that should not be an amalgam restoration } \\
\text { becomes an amalgam restoration in the end.' } \\
\text { Focus group 1, P ii: 'Some of the students are wanting to do a specific type of filling } \\
\text { because they need that particular quota, and obviously, we wouldn't advocate for them } \\
\text { to do that just because they need the quota. But there are instances where that is the } \\
\text { reality.' }\end{array}$ \\
\hline $\begin{array}{l}\text { 3. What guides the } \\
\text { students' choice of dental } \\
\text { material? }\end{array}$ & $\begin{array}{l}\text { What factors in the clinic lead to } \\
\text { the decision of what dental mate- } \\
\text { rial is used? }\end{array}$ & $\begin{array}{l}\text { Focus group 2, P6: 'It's easier to place a composite than to place an amalgam. With } \\
\text { a composite, you place the material, put the light, and that's it. With an amalgam, you } \\
\text { have to cut the cavity, run to the amalgamator, mix, come back, plug. It's a cumbersome } \\
\text { process. But also I think that they prefer composite because it's less technique sensitive, } \\
\text { unlike with amalgam you have to have sound walls, the floor (of the cavity) must be } \\
\text { correct, you must have the correct angles and so on. It's easier to place a composite } \\
\text { because you just follow the cavity. So I think that pushes our students a lot to use com- } \\
\text { posite rather than amalgam.' } \\
\text { Focus group 1, Piii: 'For amalgam, the preclinical training is a little more intense than for } \\
\text { composites. Cavity preparation has to be done in a specific way. So the cut down in } \\
\text { time has obviously impacted on that. So previously, there has always been enough time } \\
\text { allocated for that. So I think that the trend is moving more towards composites.' } \\
\text { Focus group 1, Pv: 'I'll say the number one would be the difficulty of the cavity prep and } \\
\text { the difficulty of placing an amalgam. Even packing it is difficult, composite is so much } \\
\text { easier, so they are going to choose the easier route.' }\end{array}$ \\
\hline $\begin{array}{l}\text { 4.Correct disposal of } \\
\text { amalgam waste products }\end{array}$ & $\begin{array}{l}\text { How is amalgam waste disposed of } \\
\text { during clinical training? }\end{array}$ & $\begin{array}{l}\text { Focus group 2, P6: 'amalgam disposal is a problem.' } \\
\text { Focus group 1, P6: 'the university does not have the correct waste disposal facilities.' }\end{array}$ \\
\hline 5. Patient preference & $\begin{array}{l}\text { Patients are becoming increasingly } \\
\text { aware dentistry and are making } \\
\text { informed choices }\end{array}$ & $\begin{array}{l}\text { Focus group 2, P7: ' ... even the poorest of patients doesn't want a 'black filling in their } \\
\text { mouth.' } \\
\text { Focus group 1, Pv: 'Our patients didn't really want it, they would ask for tooth coloured, } \\
\text { but because of quota, we had to place amalgams.' } \\
\text { Focus group 2, P8: 'dentistry is going towards aesthetics now, and they need to be good } \\
\text { at it.' }\end{array}$ \\
\hline $\begin{array}{l}\text { 6.Occupational and } \\
\text { environmental risks using } \\
\text { dental amalgam }\end{array}$ & $\begin{array}{l}\text { The clinicians and staff were aware } \\
\text { of the risks associated with the } \\
\text { mercury content in amalgam }\end{array}$ & $\begin{array}{l}\text { Focus group2, P7: 'They should phase it out...also because of the mercury content.' } \\
\text { Focus group 2, P8: 'But I have also had patients in my practice that came in to remove } \\
\text { and replace with composite because they have had medical issues with amalgam that } \\
\text { was diagnosed by a specialist.' } \\
\text { Focus group 2, P6: 'it's poisonous to practitioners.' }\end{array}$ \\
\hline
\end{tabular}

\section{Data Collection and analysis}

Two focus group discussions were conducted. Group one consisted of the clinical supervisors involved in restorative dentistry supervision at the clinical training site. The second group consisted of all academic staff, including the academic leader from the discipline. Two interviews were conducted as these staff were unable to join the focus group discussion, and the data obtained was merged with the academic group discussion. The two focus group discussions took place between March and May 2020. The researcher invited participants via email. An information sheet was given to all participants before the discussion outlining the reason for the study. A demographic sheet was sent before the meeting requesting demographic details. Participants were informed that they could withdraw from the study at any stage.

The first author collected data during both the focus group discussions. Focus group one was conducted face-to-face before the global pandemic. The second focus group was conducted virtually via Zoom. The areas explored included involvement in restorative teaching and training curriculum, guidelines for amalgam training and the future of amalgam in dental training. The interviews and focus group discussions 
were conducted in English, and audio was recorded. The researcher transcribed the discussions verbatim, and thereafter the data was cleaned before analysis.

The thematic analysis followed the six-phase thematic analysis by Braun and Clarke (2006). ${ }^{14}$ The researcher read through the transcripts several times to identify familiar patterns. Open coding was done manually by writing notes on the transcripts. Several codes were linked together to form overarching themes and sub-themes. A data verification process was conducted. The analysed data were sent to one participant from each focus group to analyse the interpreted data and provide feedback. Participants were assured of anonymity, as no names were used. Participants were given a participant ID. Focus group 1 - Participant i -vi, Focus group 2 - Participant 1-8.

A list of questions that analysed the restorative dentistry curriculum was emailed to the academic head. These questions assessed the teaching and preclinical training time that was taken for amalgam and composite resin materials. The researcher looked at the preclinical and clinical logbooks, the module templates and guidelines, and the yearbook.

\section{RESULTS}

The results are presented in three parts: demographics of participants, thematic analysis of the participants' responses, and a targeted review of the restorative dentistry curriculum. Seventeen participants were invited to participate; fourteen responded and participated, yielding an $82 \%$ response rate.

The demographic details are summarised in Table1. The average age group of participants in group 1 was 41years, and group 2 was 47,5 years. Seventy-nine percent $(n=11)$ of participants have more than twenty years of experience in their respective professions. Forty-three percent $(n=6)$ of the total participants have postgraduate degrees, with Masters $(n=2)$ and $(n=4)$ with a PhD. Sixty-four percent $(n=9)$ were females. Forty-three percent $(n=6)$ of participants had some involvement in the planning of the dental curriculum. Seventyfive percent of the participants had more than ten years of experience in restorative dentistry supervision.

\section{Focus group}

The participants' responses were broadly divided into themes, viz. the challenges faced with dental amalgam training (Table 2) and curriculum development recommendations (Table 3). The themes were further broken down into sub-themes. Some of those sub-themes identified with dental amalgam training challenges include increased student intake, clinical quota requirements, disposal of waste products, and occupational and environmental risks regarding mercury exposure.

The recommendations for training with dental amalgam included factors such as the implications of the Minamata convention, the continuing professional development of the participants, the skills gained during cavity preparations, guidelines to guide the training and quota requirements of dental materials, the awareness of the teaching trends locally, nationally and internationally. The responses are tabulated in Table 3.

Targeted review of the dental curriculum

A checklist and a list of questions was emailed to the academic leader. This revealed that second-year students were involved in preclinical training only on the dental laboratory's phantom head, while third-year students were exposed to preclinical training and clinical training at the dental training hospital. The third-year students were also involved in dental outreach programmes.

It was revealed that there are a total of 48 lectures, ten tutorials and 52 practical sessions. Whilst the handbook provides for 52 practical sessions, students do not have sufficient time. The leader reported that this is spread to observation, assisting and actual clinical work for the third years. Twelve phantom heads are available in the dental laboratory, and therefore 12 students can work at a time. The academic leader further reported that 'with more students' intake, there is less time for clinical training.' The third-year students go out on outreach programmes once a week, and students are exposed to both amalgam and composite training. The second-year preclinical training quotas require the student to perform 13 composite restorations, including all class types. Eleven amalgam restorations are required, which include all class types (except for anterior restorations). The minimum quota for the third year clinical training requires the student to perform 87 restorations, of which five must be bonded amalgam restorations of the different classes, 70 composite restorations (different classes), and ten temporary dressings and caries control restorations. The curriculum revealed that the placement of amalgam restorations had been discontinued in children's primary teeth and pregnant women. There has also been a significant reduction in the number of teeth restored by amalgam over the last ten years due to the reductions with quotas. In previous years, third-year students were required to complete a class two amalgam restoration for the examination; however, this has now changed to composite.

\section{DISCUSSION}

The teaching of dental amalgam is continuing in the discipline. The participants have revealed that the students are placing more composite restorations in the dental clinic. The teaching time for composite restorations has increased compared to teaching time for amalgam. One of the most common challenges expressed by all participants was increased student numbers at the university. Clinical supervisors have mentioned that the students' supervision and clinical teaching was greatly impeded due to the restricted time constraints. This sentiment was echoed in a study that agreed a significant problem arises when student intake needs to increase to meet the national imperative, which will further compromise the current clinical training platform. ${ }^{15}$ From the discussion, it was found that as dental therapists, the skills gained through preparing an amalgam cavity is of vital importance as dental therapy students do not have the opportunity to gain skills by preparing cast restorations as dentistry students do. However, this aspect of dental training needs to be questioned about how prepared students are for the 'real world' compared to preparing ideal cavity preparations in the preclinical laboratory. The problem with this type of training is that it is only focused on developing technical skills in a hospitaloriented care approach without a broader understanding of its application in the context of primary care orientation. ${ }^{16}$

Another challenge in training was the quota requirement for dental restorations. It has been discovered from a study carried out with dental therapy students that their preferred 
Table 3 Recommendations for curriculum development

\begin{tabular}{l|l|}
\hline Sub-theme & Description \\
\hline $\begin{array}{l}\text { 1. The Minamata Conven- } \\
\text { tion and its implications }\end{array}$ & $\begin{array}{l}\text { Most of the participants were aware } \\
\text { of the convention and its recommen- } \\
\text { dations regarding the phase-down of } \\
\text { dental amalgam }\end{array}$ \\
\hline $\begin{array}{l}\text { 2. Continuing professional } \\
\text { skills of participants }\end{array}$ & $\begin{array}{l}\text { The decisions made by the partici- } \\
\text { pants were evidence-based as the } \\
\text { participants update their knowledge } \\
\text { and skills by attending conferences, } \\
\text { reading peer-reviewed journals and } \\
\text { participating in continuous professional } \\
\text { development assessments }\end{array}$ \\
\hline
\end{tabular}

Participants agreed that amalgam cavity preparation requires more skill when teaching. However, they were divided in their opinion as to whether this was acceptable.

3.Skills gained for an amagam cavity preparation
The participants were asked where

4. The teaching and training trends regarding dental amalgam locally and internationally

respective training institutions. Partic-

ipants were trained at various South
5.Guidelines to regulate quota for dental amalgam

6.Should amalgam be replaced entirely in dental training?

\section{Participants Response}

Focus 2, P6: 'Whilst I have heard of the conference and its implications, instead of the conference trying to influence people, I think that it is a personal choice.'

Focus group 2, P5: 'I heard about the conference and the phasing down, and one of the conclusions from that conference is that until they find a total replacement material for amalgam, they will not do away with amalgam. So I think that it's still in use today because of that.'

Focus group 2, P2: 'I follow CPD events, I attend seminars and do CPD questions.'

Focus group 2, P6: 'I do quite a bit of reading on journal articles and CPD events.'

Focus group 1, P8: 'I read up on new research that comes up, and basically, I attend conferences and talk to the reps from $3 \mathrm{M}$. I educate myself with the products.'

Focus group 2, P6: 'in our university, I think that we still use it (amalgam) to ensure that students have that finer skill to cut a cavity.'

Focus group 2, P7: 'it's a nice cavity prep to start out with to teach basic concepts like resistance form, outline form and for all those kind of things and obviously for them to learn in terms of carving.'

Focus group 2, P6: 'with amalgam, you have to have sound walls, the floor (of the cavity) must be correct, you must have the correct angles and so on. Its easier to place a composite because you just follow the cavity.'

Focus group 1, Pii: 'For amalgam, the preclinical training is a little more intense than for composites. Cavity preparation has to be done in a specific way.'

Focus group 1, P5: 'I think that we are trained theoretically to conserve tooth structure, so when it comes to amalgams, it tends to destroy quite a lot of healthy tooth structure, just to retain the amalgam.'

Focus group 1, Pv: 'we have a quota as well. We still have to do a certain number of amalgams, gold as well.'

Focus group 1, P vi: 'Well, I finished off in Bangalore (India), and I came down to UWC and did my boards.....So at both institutions, amalgam was still being taught, so was composite.'

African universities and some abroad

Focus group 1, Piv: 'qualified in Kwa-Zulu Natal, .... Yes we have been doing amalgam.'

Focus group 2, P3: 'I also feel that the council and the HPCSA should give us some guidelines with regards to this as well so that we can follow their guidelines in time to come.'

Focus group 2, P6: 'In South Africa, with the HPCSA, we don't have any guidelines as

All participants agreed that there were no clear-cut guidelines from any council, such as HPCSA, to regulate the students' quotas for dental materials. Participants explained that they followed what had been carried out from previous years.

The participants had mixed reactions regarding this question, with clinical supervisors believing that amalgam stil has a place in dental training. Fifty percent of the academics felt that training in amalgam should be stopped. this.

Focus group 2, P2: 'The only input that I have given was for the booklets, a clinical record book. I just go according to what I am supposed to be doing from the module descriptor and the coordinator.'

Focus group 2, P6: 'The Zimbabwe dental therapist association council where they actually have instructions as to how many amalgams should be placed and which type. I know when I worked in Australia, for example, as part of our registration exams, we had to fill in a certain number of quotas, and in New Zealand as well.'

Focus group 1, Pv: 'If they came up with something that was similar with far less mercury or with no mercury, by all means, but at the moment, I wouldn't say it's obsolete yet.'

Focus group 2, Piii: 'I think that it should just be a case by case decision. It's difficult to say that one material should completely replace the other.'

Focus group 2, P6: 'My view is different, I think that we have to face reality, amalgams are outdated, they're antiquated, it's poisonous to the environment, it's poisonous to the practitioners, the waste disposal is an issue, and internationally the trend is to move away from amalgam, unfortunately, because we have been trained with amalgam, we are still doing it. my view is that we should move away from amalgam, and we should amalgam-free.'

Focus group 2, P8: 'Personally, I feel that it should. It's my personal feeling because I don't do amalgams at all. So personally, I feel that it should. I feel that they shouldn't even waste their time on amalgam. They should phase it out. Also, because of the mercury content. And when you go into private practice, you find that it is not being used.' 
material for restorations is resin composite. However, the curriculum overview revealed that dental amalgam's clinical quota requirement was still present at approximately twenty percent of the total restorations placed. This does pose a stressful exercise for students as they place composite resins more often, and towards the latter half of the year, they are obliged to place amalgam restorations just to complete clinical requirements. Additionally, dental students are faced with stress related to clinical sessions and patient management. These include late or failed patient appointments and clinical quotas. ${ }^{17}$ It has to be confirmed as to what impact the quota requirements have on patients. The quota requirement for amalgam at the institution being researched conflicts with most European studies showing that dental amalgam placement is between ten and nineteen percent at most dental schools. ${ }^{18}$

Another evident challenge is that participants showed concern regarding the safety of amalgam due to its mercury content. Most of the participants were aware that the international trend was to phase down amalgam due to that reason. They were concerned that mercury exposure could be harmful to patients, practitioners, and staff. However, in developing countries like South Africa, dental amalgam is still widely used. Oral health services are available in major urban centres but have little access to the underprivileged, disadvantaged population groups, mainly found in rural areas. Restorative dental care is extremely expensive to people living in poverty. Where oral health service exists, dental amalgam may be the material of choice in restorative dental care.

The university at present does not have an amalgam trap or correct waste disposal facilities. In various studies, this sentiment was unanimous: 'we should abandon materials that do not meet the highest biocompatibility standards or increase the patients' body burden of toxins - for the safety of the patient, families, and staff.' ${ }^{19-22}$ It was encouraging to find out that the university's dental curriculum is keeping up to date and on-trend with the European Union to stop the placement of dental amalgam in children and pregnant women. ${ }^{23}$ This bodes well for the future dental therapists' approach to paediatric dentistry. Dental therapists' should be encouraged not to place dental amalgam on primary teeth, as well as on children under 15 years of age and in this case GIC's or compomer should be the material of choice.

It was evident from the discussion that a challenge identified by the participants is that there is a conflict between the theoretical knowledge and that which is expected in the clinical requirements. Participants have stated that the theory being taught teaches students to conserve tooth structure, but amalgam cavity preparation requires tooth structure removal to ensure retention. The quotas still require students to perform amalgam restorations. The need and emphasis for minimal tooth removal and minimal intervention dentistry do not translate into the clinical quotas required. The skills required for an amalgam preparation are still fundamentally based on the modified technique by GV Black, which requires the removal of a healthy tooth structure to ensure adequate mechanical retention. ${ }^{24}$ Data from the focus group discussions showed that clinical supervisors feel a need to reduce amalgam and use it only in areas where moisture control is difficult or based on individual case requirements. Participants found that students were competent with composite material even in multi-surface cavities. The dental curriculum revealed that the teaching includes bonded amalgam, which reduces the need for sound tooth removal to accommodate retention and resistance. The adhesive system introduced in bonded amalgam allows for less tooth structure removal and minimises microleakage. ${ }^{25}$

One of the participants' recommendations expressed a desire for more clinical time for students to enhance their clinical expertise with their theoretical knowledge. The data indicated a strong propensity towards composite restorations, but participants still feel that it is essential for students to gain amalgam preparations' clinical expertise even if it is only in the preclinical phase. There was a need to reduce the actual clinical quota for amalgam restorations in the clinic. The choice of material should depend purely on a case -by case indication. The authors believe that amalgam restorations should be restricted to class ii and multi-surface restorations if at all necessary.

The majority of the academic focus group participants were aware of the Minamata Convention compared to the clinical supervisors, where just seventeen percent of the participants had heard of it. Some of the key objectives of the convention included adopting national objectives aimed at minimising mercury usage; promoting the use of cost-effective mercury-free alternatives, the promotion of research and development of mercury-free materials for dental restoration; promoting the use of best environmental practices in dental facilities to reduce the release of mercury and mercury compounds to water and land. ${ }^{26}$

However, all participants were aware of the phase-down of dental amalgam. Their choice towards composite restoration was not guided by the Minamata Convention but rather by the need for aesthetics and minimal tooth removal. The participants were all aware of the international trend regarding dental amalgam and its phase-down, and many have felt that the university should also follow in that direction. One of the Minamata Convention requirements is that all facilities should have the correct disposal system for dental amalgam. The university being researched does not comply.

The cost of dental materials emerged as another factor to consider, especially in a developing country like South Africa, where the majority of the population access public healthcare. These facilities usually have a shortage of electricity, water, and modern equipment to facilitate the placement of techniquesensitive dental materials such as dental composite. Dental amalgam is used in large carious areas, making it the material of choice when patients present for treatment due to its relatively lower cost, ease of use, and longevity of the material. The complete phase-out of amalgam may widen oral health inequalities unless a cheaper, longer-lasting alternative is available to primary health care providers. ${ }^{26}$ Participants have stated that some medical aid providers do not pay for composite resins placement, which is seen as a cosmetic procedure. There must be a collaboration between private medical aid providers and the local health governing authorities to educate them about restorative materials and their applications. Consequently, the complete phase-out of dental amalgam will not be feasible as most students will be employed in the private sector, and some medical aids will still only reimburse for amalgam restorations. 
Participants have also stated that there are currently no guidelines from any regulatory health council or governing body to regulate the dental curriculum and the number of restorations placed. The current dental curriculum has followed what was previously done over the years. It is expected that dental schools' academic leaders in South Africa can reach a common consensus regarding curriculum input.

The participants keep up to date with their continuing educational knowledge by attending conferences, reading journals, partaking in online CPD activities and webinars. Therefore, most of them are well aware of how the trend in dental restorative materials is evolving.

Participants displayed a mixed response when the question was posed if dental amalgam should be replaced entirely. Whilst there is concern regarding amalgam and its mercury content; its poor aesthetics; its removal of healthy tooth structure, and its staining of the tooth and surrounding tissues, there should be an equal concern with composites and its concern with micro-leakage, secondary caries, biocompatibility with oral tissues and polymerisation shrinkage. Participants have commented that until a suitable material with similar strength properties and affordability of amalgam is not found, it is unlikely that dental amalgam can be totally replaced. It was also evident from the discussion that all clinical supervisors felt that amalgam should still be available in the dental clinic, compared to twenty-five percent of dental academics who felt that amalgam should be completely replaced.

The demand for aesthetics has been noted since the 1970's when the aesthetic revolution began. ${ }^{27}$ This could be seen as either a bane or a boon, as patients were demanding their old amalgam restorations to be replaced. ${ }^{27}$ Some patients were concerned about mercury's toxicity, but the undeniable reason was aesthetics. ${ }^{28}$

This was evident from the first phase of the study by the above authors, which assessed the students' choice of material, and aesthetics emerged as the fundamental reason. The participants have indicated a trend towards minimal intervention dentistry. This includes minimal caries removal to ensure tooth preservation. ${ }^{29}$ Minimal intervention dentistry (MID) also includes principles of correct oral hygiene, dietary and lifestyle changes, and the application of topical fluoride products and bonded amalgam. ${ }^{29}$ This knowledge should be integrated into the curriculum of the third-year dental students as well. Presently this is conducted in the second year. Consequently, with the global Covid-19 pandemic, dentistry should undergo a reform where it should be less invasive and more preventive, reducing the need for aerosolgenerating procedures. ${ }^{30}$

\section{CONCLUSION}

The teaching and training of dental amalgam is still an integral part of the university's dental restorative curriculum. The study revealed that the academics and the clinical supervisors had shown a stronger affinity towards the placement of composite restorations rather than amalgam. Over the years, composite resins have been taught extensively, encompassing a major portion of the dental restorative curriculum. Both the clinical supervisors and dental academics have expressed a need for the clinical quota to be revised. The amalgam restorations should be placed on a case-by-case clinical decision rather than quota driven. The dental curriculum should become more relevant for these changing times to reduce dental amalgam restorations further.

\section{DECLARATIONS}

Acknowledgements

The authors would like to thank the participants for their invaluable input in the focus group discussions.

\section{Funding}

The authors received no financial support for the research, authorship, and publication of this article.

All authors read and approved the final manuscript.

Ethics approval and consent to participate

The Social Sciences and Humanities Ethics Committee of the University of KwaZulu-Natal provided ethical approval (HSSREC/00000622/2019). All participants consented to participate as well as for an audio recording.

\section{Competing interests}

The authors declare that they have no competing interests.

\section{References}

1. World Health Organization. Sugars and dental cariesTechnical information note. Available from https://www.who.int/oral_health/ publications/sugars-dental-caries-keyfacts/en/ (Accessed 02 March 2021)

2. Schulmann, J. The Stages of Tooth Decay: What They Look Like. Healthline, 30 July 2020. Available from https://www. healthline.com/health/dental-and-oral-health/tooth-decay-stages (Accessed 02 March 2021)

3. WebMD. Dental Health and Tooth Fillings.WebMD Medical Reference, reviewed by Michael Friedman, DDS on 10 October 2019. Available from https://www.webmd.com/oral-health/guide/ dental-health-fillings (Accessed 02 March 2021)

4. Soni R, Bhatnagar A, Vivek R, Singh R, Chaturvedi TP, Singh A. A systematic review on mercury toxicity from dental amalgam fillings and its management strategies. Journal of Scientific Research. 2012;56(2012):81-92. Available from https://www.bhu.ac.in/ journal/vol56-2012/BHU-7.pdf (Accessed 02 March 2021)

5. Auster P. Evolution and Revolution: Groundbreaking changes in Composite Dentistry. Dentistry Today, 01 February 2019. Available from https://www.dentistrytoday.com/articles/10522 (Accessed 02 March 2021)

6. Singh H, Kaur M, Dhillon JS, Mann JS, Kumar A. Evolution of restorative dentistry from past to present. Indian J Dent Sci. 2017;9:38-43. doi: 10.4103/0976-4003.201634

7. Kateeb ET, Warren JJ. The transition from amalgam to other restorative materials in the U.S. predoctoral pediatric dentistry clinics. Clin Exp Dent Res. 2019 Jun 12;5(4):413-419. doi: 10.1002/cre2.196.

8. Lynch $\mathrm{CD}$, Wilson $\mathrm{NH}$. Managing the phase-down of amalgam: Part I. Educational and training issues. Br Dent J. 2013 Aug;215(3):109-13. doi: 10.1038/sj.bdj.2013.737.

9. Ylinen K, Löfroth G. Nordic dentists' knowledge and attitudes on dental amalgam from health and environmental perspectives. Acta Odontol Scand. 2002 Oct;60(5):315-20. doi: 10.1080/00016350260248319.

10. Pani SC, Al Abbassi MF, Al Saffan AD, Al Sumait MA, Shakir AN. Factors influencing Saudi dental students' preference of amalgam or composite for posterior dental restorations. Saudi J Oral Sci 2014;1:30-36. doi: 10.4103/WKMP-0056.124183

11. Alexander G, Hopcraft MS, Tyas MJ, Wong RHK. Dental educators attitudes towards the teaching of dental amalgam: A mixed method analysis. European Journal of Dental Education. 2020;24(2): 282-291. https://doi.org/10.1111/eje.12496 
12. Zabrovsky A, Neeman Levy T, Bar-On H, Beyth N, Ben-Gal G. Next generation of dentists moving to amalgam-free dentistry: Survey of posterior restorations teaching in North America. Eur J Dent Educ. 2019 Aug;23(3):355-363. doi: 10.1111/eje.12437.

13. Umesi DC, Oremosu OA, Makanjuola JO. Amalgam phase down: baseline data preceding implementation in Nigeria. Int Dent J. 2020 Jun;70(3):161-166. doi: 10.1111/idj.12536.

14. Braun V, Clarke V. Using thematic analysis in psychology. Qualitative Research in Psychology. 2006;3(2):77-101. doi: 10.1191/1478088706qp063oa

15. Moodley I, Singh S, Creating opportunities for interprofessional, community-based education for the undergraduate dental therapy degree in the School of Health Sciences, University of KwaZulu-Natal, South Africa: Academics' perspectives AJHPE. 2018;10(2):96-100. doi:10.7196/AJHPE.2018.v10i2.1005.

16. Frenk J, Chen L, Bhutta ZA, Cohen J, Crisp N, Evans T, Fineberg H, Garcia P, Ke Y, Kelley P, Kistnasamy B, Meleis A, Naylor D, Pablos-Mendez A, Reddy S, Scrimshaw S, Sepulveda J, Serwadda D, Zurayk H. Health professionals for a new century: transforming education to strengthen health systems in an interdependent world. Lancet. 2010 Dec 4;376(9756):1923-58. doi: 10.1016/S0140-6736(10)61854-5.

17. Bhayat A, Madiba TK. The self-perceived sources of stress among dental students at a South African Dental School and their methods of coping. S. Afr. dent. j. 2017;72(1):6-10. Available from http://www.scielo.org.za/scielo.php?script=sci_ arttext\&pid=S0011-85162017000100005 (Accessed 02 March 2021)

18. European Commission and Deloitte. Assessment of the feasibility of phasing-out dental amalgam - Final report (under Framework Contract No. ENV.C.4/FRA/2015/0042 - Service request 15), 17 June 2020. Available from https://circabc. europa.eu/sd/a/4fd46a0f-54aa-48c6-8483-288ad3c1c281/ Dental\%20Amalgam\%20feasbility\%20study\%20-\%20 Final\%20Report.pdf (Accessed 27 August 2021)

19. SCENIHR (Scientific Committee on Emerging and Newly Identified Health Risks). Possible effects of Electromagnetic Fields (EMF) on Human Health. 21 March 2007. Available from https://ec.europa.eu/health/ph_risk/committees/04_scenihr/ docs/scenihr_O_007.pdf (Accessed 02 March 2021)

20. Parvin R. Mercury in dentistry. Available from https://www. academia.edu/34790382/Mercury_in_Dentistry (Accessed 02 March 2021)

21. Sahani M, Sulaiman NS, Tan BS, Yahya NA, Annual ZF, Wan Mahiyuddin WR, Khan MF, Muttalib KA. Mercury in dental amalgam: Are our health care workers at risk? Journal of the Air \& Waste Management Association. 2016;66(11):1077-1083. doi: 10.1080/10962247.2016.1188866

22. Warwick R, O'Connor A, Lamey B. Mercury vapour exposure during dental student training in amalgam removal. J Occup Med Toxicol. 2013 Oct 3;8(1):27. doi: 10.1186/1745-6673-8-27.

23. Anastasio M. EU countries urged to ban mercury in dental fillings on children and pregnant women. META from the European Environmental Bureau. 24 July 2018. Available from https://meta.eeb.org/2018/07/24/eu-countries-urged-to-banmercury-in-dental-fillings-of-children-and-pregnant-women/ (Accessed 02 March 2021)

24. Walford P. Design Principles For Class II Preparations. Oral Health, 01 December 2012. Available from https://www. oralhealthgroup.com/features/design-principles-for-class-iipreparations/ (Accessed 02 March 2021)

25. Bharti R, Wadhwani KK, Tikku AP, Chandra A. Dental amalgam: An update. J Conserv Dent. 2010;13(4):204-208. doi:10.4103/0972-0707.73380

26. Aggarwal VR, Pavitt S, Wu J, Nattress B, Franklin P, Owen J, Wood D, Vinall-Collier K. Assessing the perceived impact of post Minamata amalgam phase down on oral health inequalities: a mixed-methods investigation. BMC Health Serv Res. 2019;19:985. https://doi.org/10.1186/s12913-019-4835-1

27. Sadowsky SJ. An overview of treatment considerations for esthetic restorations: a review of the literature. J Prosthet Dent. 2006 Dec;96(6):433-42. doi: 10.1016/j.prosdent.2006.09.018.

28. Schmidt CJ, Tatum SA. Cosmetic dentistry. Curr Opin
Otolaryngol Head Neck Surg. 2006 Aug;14(4):254-9. doi: 10.1097/01.moo.0000233596.68928.39.

29. Walsh LJ, Brostek AM. Minimum intervention dentistry principles and objectives. Aust Dent J. 2013 Jun;58 Suppl 1:3-16. doi: 10.1111/adj.12045.

30. Watt RG. COVID-19 is an opportunity for reform in dentistry. Lancet. 2020 Aug 15;396(10249):462. doi: 10.1016/ S0140-6736(20)31529-4. 